\title{
Finite Element Analysis on All on Four Implant Screw Retained Mandibular Fixed Prosthesis. (Material Selection Role)
}

\author{
Salah A. Youssef ${ }^{* 1,2}$, Rami Mohammed Galal ${ }^{3}$, Ghada E. Hamza ${ }^{4}$, Ghith Fayez Saeed Aldhahri ${ }^{5}$, Ahmad
} Ramzi Abdu Alzaylaei ${ }^{5}$, Mohammed Saleh Mohammed Alamoudi ${ }^{5}$, Abdullah Abdulrahman Ahmad Benjabi ${ }^{5}$, Yousef Hatem Jayar ${ }^{\mathbf{5}}$, Ammar Abdulrahim Abdulqahhar Khoja ${ }^{\mathbf{5}}$, Ahmad Mohammad Salem Alsaiary ${ }^{\mathbf{5}}$, Muhanad Naser Aljuhani ${ }^{5}$, Abdulrahman Omar Ali Sanyour ${ }^{5}$, Bader Obidullah Alkhozai ${ }^{5}$, Adnan Madani Mohammed Khamis ${ }^{5}$,

Salma Sulaiman Alghalayini ${ }^{6}$

${ }^{1}$ Department of Restorative and Prosthetic Dental Sciences, College of Dentistry, Dar Al Uloom University, Riyadh, Saudi Arabia

${ }^{2}$ Crown \& Bridge Department, Faculty of Oral and Dental Medicine, Al Azhar University, Assuit Branch, Egypt

${ }^{3}$ Assistant Professor, Fixed and Removable Prosthodontics Department, National Research Centre, Assistant Professor Fixed Prosthodontics Department, Al Nahda University (NUB), Egypt

${ }^{4}$ Researcher, Fixed and Removable Prosthodontics Department, National Research Centre, Egypt

${ }^{5}$ Alfarabi Private College for Dentistry and Nursing, Jeddah, Saudi Arabia

${ }^{6}$ Restorative Dentistry Department, AL-Farabi Dental and Nursing College, Jeddah, Saudi Arabia

*Corresponding author: Salah A. Youssef; salah.a@dau.edu.sa

Received: 10 December 2020;

Accepted: 26 December 2020;

Published: 28 December 2020

\begin{abstract}
Aim: to indicate the importance of adequate selection of all on four-fixed implant supported hybrid mandibular prosthesis material to reduce bone stresses. Materials and methods: one three-dimensional simplified geometric model, for bone and fixed prosthesis, was created by using engineering CAD/CAM software. On the other hand, implant system manufacturer data gave sufficient geometrical data to model it exactly. The modelled part was transferred to ANSYS for assembly, meshing, and analysis. Three overlying materials were tested; Acrylic, Polycarbonate, and Zirconia above the cobalt chromium bar. The lowest area of the cortical bone was set to be fixed in place as boundary condition. While unilaterally load of $250 \mathrm{~N}$ was applied vertically on central fossa of first and second molars as two loading cases. Results: changing overlying material resulted in, cortical bone and implant complex receiving Von Mises stress in sequence with material rigidity. The more rigid the overlying material the less bone stresses with first molar loading, while, opposite trend (sequence) appeared with second molar loading. On the other hand, bar, coping, screws, mucosa, and spongy bone deformations and stresses decreased with increasing overlying material rigidity. Where, all the model components showed stresses and deformations within the physiological limits. Conclusions: More rigid overlying material is recommended to reduce stresses on bar, coping, screws, mucosa, and spongy bone. Overlying material selection for cortical bone and implant complex is extremely tricky. That it showed same behaviour as other soft tissues with applying load close to the bar (short cantilever arm), then inverted behaviour with shifting the applied load away from first to second molar (increasing cantilever arm).
\end{abstract}

Keywords: All on four, overlying material, FEA, Acrylic, Polycarbonate, Zirconia

\section{Introduction}

Rehabilitation of edentulous arches with implant-supported or implant-retained prostheses is considered a predictable and successful treatment modality. It provides better retention and stability, improving function and aesthetics as well as preserving the residual bone, especially in the mandible ${ }^{[1-3]}$.

The all on four concepts depends on putting four implants for immediate function to rehabilitate the full arch ${ }^{[4]}$. This is done by putting 4 implants: 2 implants posteriorly with 45 degrees angulation and 2 anterior implants placed axially, and it is very 
important to have proper primary stability ${ }^{[5]}$. The long term outcome of full arch prosthesis with the all on 4 concept was assessed: the cumulative survival rate was found in the mandible (93\% survival rate with up to 18 years follow up) ${ }^{[6]}$. The all on 4 concepts showed survival of 97.6-100\% under 2 years ${ }^{[7]}$. From 3-5 years, the survival was $96-99 \%$. This concept is well assessed in a systematic review ${ }^{[9]}$. It was found before in a 1-year assessment of hybrid prosthesis for fixed full arch rehabilitation with the all on 4 concept promising outcomes regarding bone loss, survival and patient satisfaction ${ }^{[10]}$.

Sometimes, complications regarding superstructure (type of ceramic, metal-ceramic, metal-resin or ceramic - ceramic) can occur ${ }^{[11]}$. This was found in previous retrospective study. ${ }^{[12]}$ So, superstructure is a very important parameter to be studied ${ }^{[13]}$. In mandibular all on 4 implants, the cantilever extension and time of surgery should be lessened as much as possible; the superstructure should provide good aesthetics, strength and biocompatibility ${ }^{[14]}$.

Computer aided designed and computer aided manufacturing (CAD/CAM) technology have improved the use of zirconia prostheses ${ }^{[15]}$. It increased the degree of precision of these zirconia implant supported full arch prostheses. The metal framework gives then of splinting and helps to keep the stresses always within the permissible limit with subsequent predictable osseointegration ${ }^{[16]}$. The prosthesis metal framework prevents fracture and may decrease bending, reduce stresses on bone and gives the needed hardness during implant scaring period ${ }^{[17]}$. Metal substructure with acrylic overlying material is preferred when there is moderate or severe bone loss to help in lips and cheeck support ${ }^{[18]}$. Polycarbonate was used before as a crown material over mini implants in case of growing patients as a temporary solution for the situation in young age ${ }^{[19]}$.

This classic bar covered with resin material has good prognosis but with time less aesthetic results, also the resin material had no good response with subjected loads ${ }^{[20]}$. So recently, the overlying material over the bar is zirconia to have better aesthetic results and resistance to loads with time ${ }^{[21]}$.

This research is aiming to examine different cobalt chromium bar overlying materials used for all on four prosthesis and its role in distributing the applied load on the underneath structures using finite element analysis.

\section{Materials and Methods}

A simplified 3D model for mandibular bone and over denture was created based on similar studies ${ }^{[34-36]}$, where bone height was set to be $24 \mathrm{~mm}$, and gingival height of $2 \mathrm{~mm}$. The four implants of $11.5 \mathrm{~mm}$ length and $4.0 \mathrm{~mm}$ diameter (Neobiotech Co., Ltd., Los Angeles, CA, USA) were modelled and placed perfectly as two vertically in canine region, and two inclined implants ( $17^{\circ}$ distally) at the second pre-molar. The implant complex was modelled based on manufacturer data. Complete osseointegration was assumed, where all used materials were assumed isotropic, homogenous and linearly elastic and its properties are listed in Table 1.

Table 1: The used material properties

\begin{tabular}{|l|l|l|}
\hline & $\begin{array}{l}\text { Young's } \\
\text { modules [MPa] }\end{array}$ & $\begin{array}{l}\text { Poisson's } \\
\text { ratio }\end{array}$ \\
\hline Overdenture (acrylic) & 2,700 & 0.35 \\
\hline Overdenture (Polycarbonate) & 13,500 & 0.31 \\
\hline Overdenture (Zirconia) & 200,000 & 0.35 \\
\hline Mucosa & 10 & 0.40 \\
\hline Bar: $\mathrm{C}_{\mathbf{r}} \mathrm{C}_{\mathbf{o}}$ & 210,000 & 0.29 \\
\hline Implant (Titanium) & 110,000 & 0.35 \\
\hline Cortical bone & 13,700 & 0.30 \\
\hline Cancellous bone & 1,370 & 0.30 \\
\hline
\end{tabular}

The finite element models' components (prescribed in this vitro study) as the implants, attachments, screws, copings, over denture, mucosa, cortical and cancellous bones were created on "Autodesk Inventor" Version 8 (Autodesk Inc., San Rafael, CA, USA) as presented in Figure 1. These components were exported as STEP files, to be assembled and meshed in ANSYS environment (ANSYS Inc., Canonsburg, PA, USA). The meshing software was ANSYS Workbench version 16. Mesh density was examined and optimized for accuracy and calculation time. Number of nodes and elements of each component were listed in Table 2, and screen shots for meshed components were presented in Figure 2.

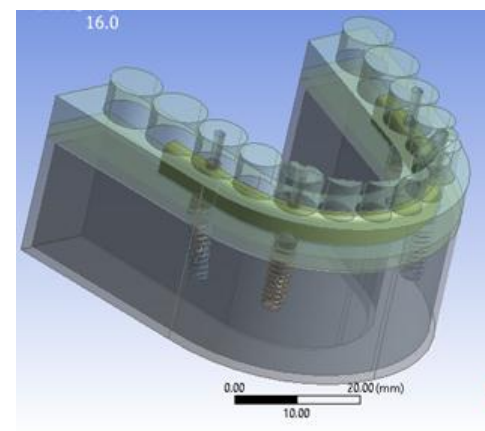

(a)

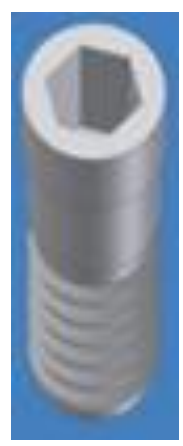

(d)

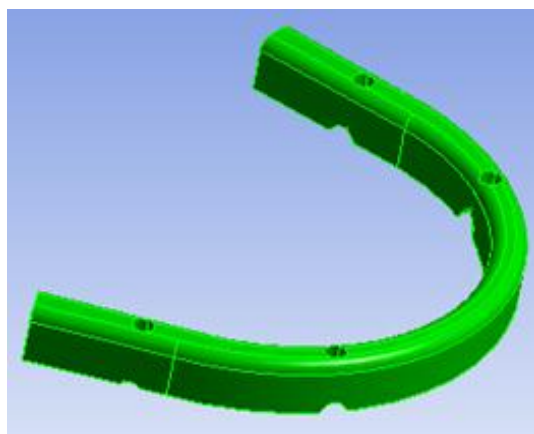

(b)

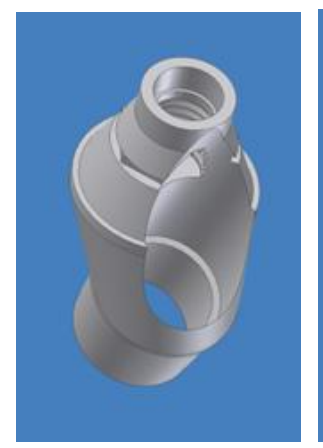

(f)

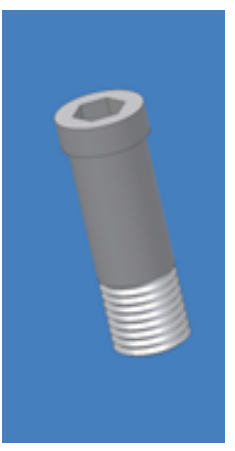

(g)

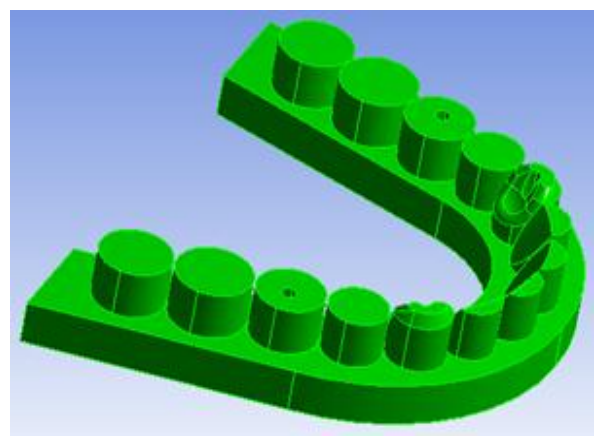

(c)

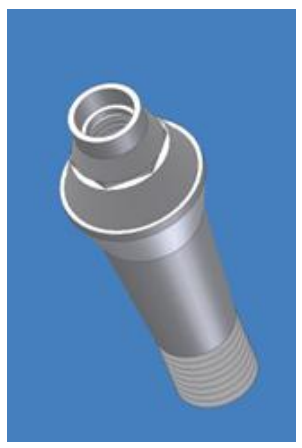

(h)

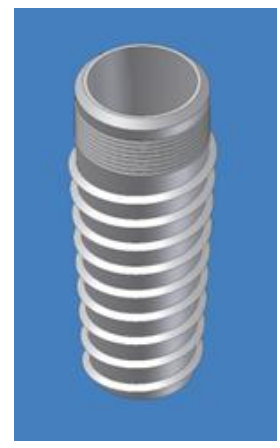

(i) 
Figure 1: Sample of modelled components and its assembly as (a) complete model, (b) bar, (c) over denture, (d) short screw, (e)coping, (f) angulated attachment, (g) long screw, (h) straight attachment, (i) implant

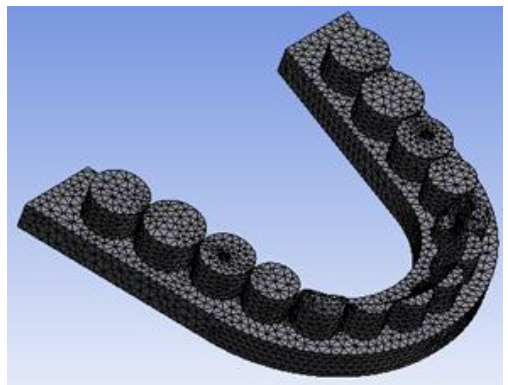

(a)

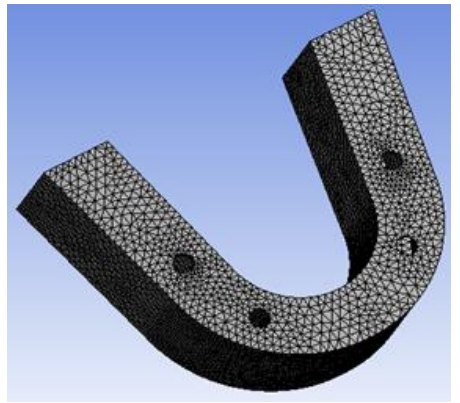

(d)

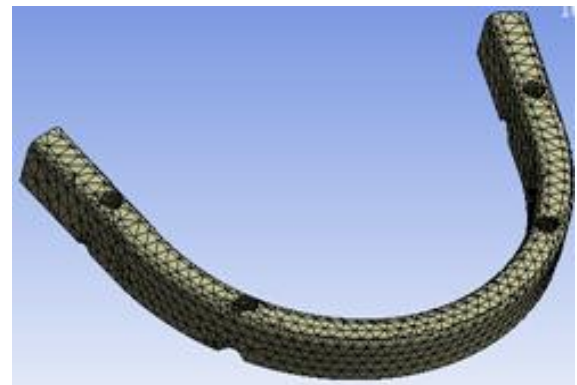

(b)

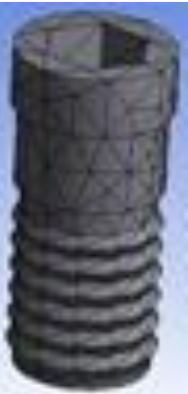

(e)

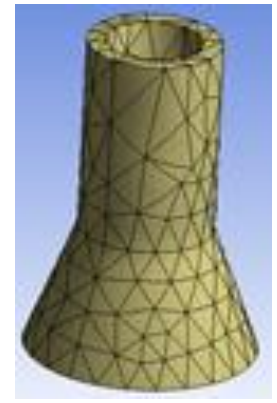

(f)

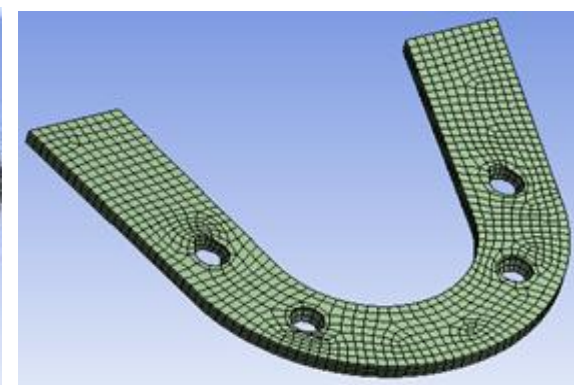

(c)

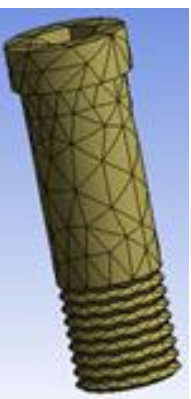

(g)

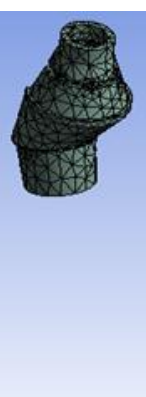

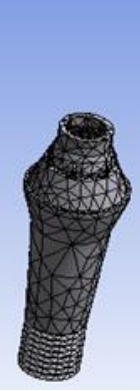

(h)

Figure 2: Sample of meshed model components as; (a) overdenture, (b) bar, (c) mucosa, (d) cortical bone, (e) short screw, (f) coping, (g) long screw, (h) angulated and straight attachments

Table 2: Mesh density

\begin{tabular}{|l|l|l|}
\hline & Nodes & Elements \\
\hline Overdenture & 107,050 & 70,814 \\
\hline Bar & 20,496 & 12,779 \\
\hline Mucosa & 14,636 & 2,652 \\
\hline Cortical & 132,260 & 81,475 \\
\hline Cancellous & 299,817 & 207,147 \\
\hline 4 x Implants & 138,145 & 89,763 \\
\hline 4 x Attachments & 58,921 & 38,325 \\
\hline 2 x Long screws & 6,573 & 3,733 \\
\hline 4 x Small screws & 17,037 & 10,501 \\
\hline 4 x Copings & 11,698 & 6,164 \\
\hline
\end{tabular}

The lowest area of the cortical bone was set to be fixed in place as boundary condition. While unilaterally load of $250 \mathrm{~N}$ was applied vertically on central fossa of first and second molar as two loading cases. Linear static analysis and solid modelling were performed on a personal computer Intel Core i7, processor $2.4 \mathrm{GHz}, 6.0 \mathrm{~GB}$ RAM. The model was verified against similar studies and showed good matched results ${ }^{[34-36]}$.

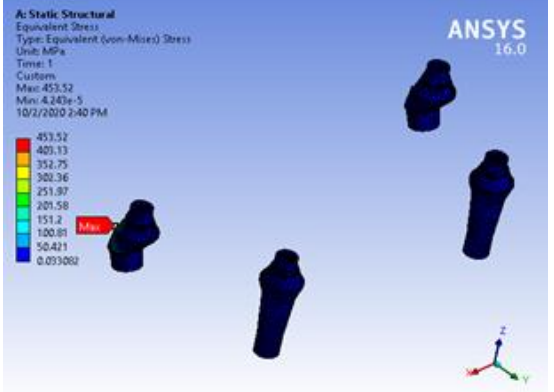

(a)

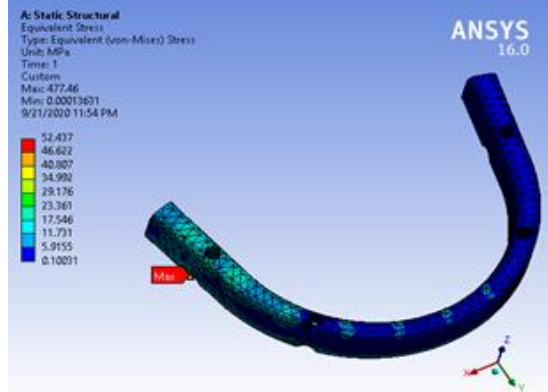

(b)

\section{Results}

The results obtained from the six cases showed that all model components' stresses and distributions did not exceed the physiological limits. That the applied load was distributed among all model components showing the extreme values near closest supporting implant. Figure 3 demonstrated sample of Von Mises stress distribution on selected components.

Figure 3: Sample of Von Mises stress distribution as; (a) Attachments, (b) bar, (c) cortical bone 
Comparisons between maximum Von Mises stress and total deformation appeared in the six studied cases can help to extract conclusions and recommendations. Figures 4 and 5 illustrate sample of these comparisons as total deformations and Von Mises stress respectively.

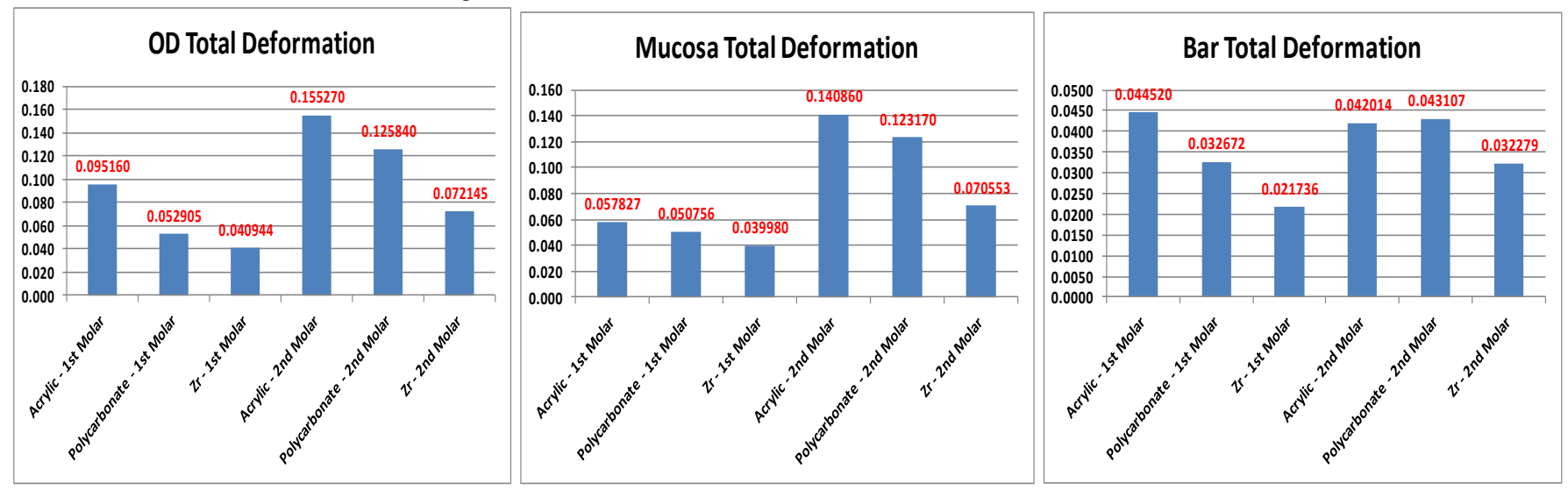

Figure 4: Maximum total deformation values comparison on selected model components

Acrylic over denture showed higher total deformation than polycarbonate, which in turn was higher than Zirconia one under both of the loading cases. This results' sequence was clearly appearing on over denture, bar, and mucosa. On the other hand, this sequence was inverted by moving the applied load from first to second molar (increasing cantilever arm) on implant complex and bone.
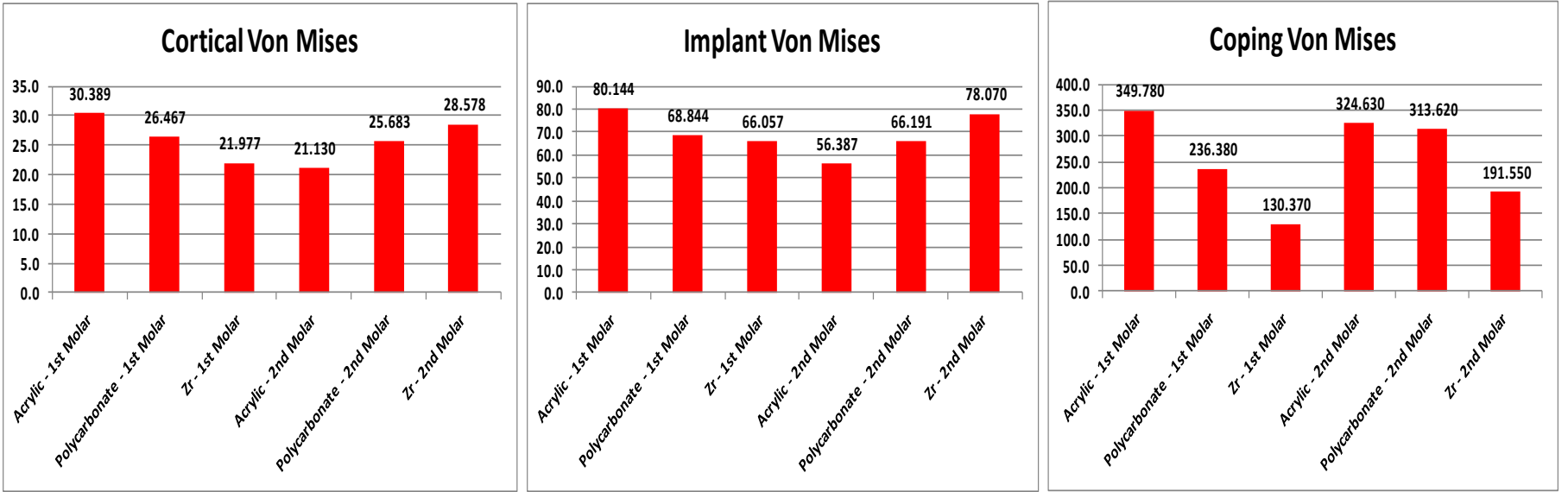

Figure 5: Maximum Von Mises stress values comparison on selected model components

Trend of Von Mises stress was similar to total deformation with changing over denture material or loading position. That, Von Mises stress appeared on implants, attachments, screws, coping, cortical, and spongy bone showed inverted behaviour by changing the loading position (increasing cantilever arm).

\section{Discussions}

The present study used finite element analysis to assess the biomechanics of all on four implant-supported prosthesis. This treatment modality gives several advantages over using short implants in the posterior region, it has more bone to implant contact area and less cantilever extension, also it decreased the overall cost. So especially old patients who had extensive bone loss with age prefer this treatment ${ }^{[22]}$. It is preferred regarding aesthetics, function and phonation over traditional removable full denture.

The prosthetic complications are ranging from 10.8\%-30\% in mandible full rehabilitation prostheses. Most of the complications occur when there is no strong reinforcement structure for the prosthesis. The use of metal framework substructure may contribute to prevention of future complications as found in a study by Silva et al in $2018^{[23]}$. Traditionally, acrylic can be used as an overlying veneer material over the metal substructure ${ }^{[24]}$. Polycarbonate material is used over implants in some situations as with mini implants used with growing patients ${ }^{[19]}$. Zirconia is the recent material used for better aesthetics with time and better mechanical performance ${ }^{[21]}$.

The more rigidity of over denture material the better load transfer mechanism (better-distributed stresses) on underneath structures ${ }^{[26]}$. Rubo and Souza proved this in $2008{ }^{[25]}$ as they found that the more rigid the structure the more the stress dissipation and less damage to the screws. In another study by Tribst et al in 2017, it was found that the use of metal or zirconia materials with high rigidity would not concentrate the stresses over one of the abutments specifically as what would happen if less rigid material is used ${ }^{[27]}$.

For short cantilever arm (first molar loading), the resultant stresses and deformations decreased with selecting over denture material with higher rigidity. This finding matched mechanisms of loading transfer that rigid over denture help in distributing the applied load through the bar to supporting implants. Horita et al also in 2017 found that there is a relation between increasing the cantilever length and increasing the stresses over the implants ${ }^{[28]}$.

For longer cantilever arm (second molar loading), the resultant stresses and deformations increased with selecting material with higher rigidity. This finding matched may be referred to changing load transfer mechanism. That less rigid material 
distributes the applied load to underneath tissues and the rest goes to the bar then implants to bone, which might reduce bone and implant stresses and deformation. On the other hand, the more rigid over denture material transfers the load direct to bar then implants and bone via high bending effect that increase stresses and deformations on implant complex and cortical bone. This is augmented by Kumari et al in 2020 as they assessed different cantilever lengths and found that with increasing the cantilever length more stresses are exerted over the terminal implant ${ }^{[29]}$.

Bar presence resulted in over constrained implants that increase its stresses levels under loading in comparison to separate supporting implants ${ }^{[30,31]}$. Although Vafaei et al in 2011 found that the use of bar in the long bar showed more appropriate stress distribution $^{[32]}$.

All on four restorations as a fixed prosthesis comparison with traditional fixed prosthesis supported by four implants or removable ones like locators and ball and socket attachment should be carried out later on that the differenced might be small or negligible. However Ebadian et al in 2015 stated that implant splinting using the bar gives mare favourable results due to more implant stability ${ }^{[33]}$.

\section{Conclusions}

More rigid over denture material is recommended to reduce stresses on bar, coping, screws, mucosa, and spongy bone. Prosthesis overlying material selection for cortical bone and implant complex is extremely tricky. That it showed same behaviourr5444444465r5 as other soft tissues with applying load close to the bar (short cantilever arm), then inverted behaviour with shifting the applied load away from first to second molar (increasing cantilever arm).

\section{Ethical Approval}

This research does not require ethical approval and followed the Helsinki declaration.

\section{Acknowledgment}

The authors are grateful to the Deanship of Graduate Studies and Research in Dar Al Uloom University for their financial support.

\section{References}

[1] Walid Al-Jallad and Jamil Owda. Implant overdenture A review to highlight the concept. J Dent Oral Health Cosmesis 2020, 5: 015.

[2] Fadi Al Farawati and Pranai Nakaparskin. What is the optimal material for implant prosthesis? Dental clinics, volume 63, issue 3, p 515-530, July 01, 2019.

[3] Rami M. Galal, Salah A.Yousief, Waleed M. S. Alqahtani. Clinical and Radiographic Outcomes of Three Different Loading Protocols for Single-ImplantSupported Prostheses: A Randomized Controlled Trial. J Int Oral Health 2018; 10:180-6.

[4] Maló, P.; de Araújo Nobre, M.; Lopes, A.; Francischone, C.; Rigolizzo, M. "All-on-4" immediate-function concept for completely edentulous maxillae: A clinical report on the medium ( 3 years) and long-term (5 years) outcomes. Clin. Implant Dent. Relat. Res. 2012, 14, e139-e150. [CrossRef]
[5] Maló, P.; Lopes, A.; de Araújo Nobre, M.; Ferro, A. Immediate function dental implants inserted with less than $30 \mathrm{Ncm}$ of torque in full-arch maxillary rehabilitations using the All-on-4 concept: Retrospective study. Int. J. Oral Maxillofac. Surg. 2018, 47, 1079 1085. [CrossRef]

[6] Maló, P.; de Araújo Nobre, M.; Lopes, A.; Ferro, A.; Botto, J. The All-on-4 treatment concept for the rehabilitation of the completely edentulous mandible: A longitudinal study with 10 to 18 years of follow-up. Clin. Implant. Dent. Relat. Res. 2019, 21, 565-577. [CrossRef] [PubMed]

[7] Lopes, A.; Maló, P.; de Araújo Nobre, M.; SánchezFernández, E.; Gravito, I. The NobelGuide ${ }^{\circledR}$ All-on-4® Treatment Concept for Rehabilitation of Edentulous Jaws: A Retrospective Report on the 7-Years Clinical and 5-Years Radiographic Outcomes. Clin. Implant Dent. Relat. Res. 2017, 19, 233-244. [CrossRef]

[8] Hopp, M.; de Araújo Nobre, M.; Maló, P. Comparison of marginal bone loss and implant success between axial and tilted implants in maxillary All-on-4 treatment concept rehabilitations after 5 years of follow-up. Clin. Implant Dent. Relat. Res. 2017, 19, 849-859. [CrossRef]

[9] Soto-Penaloza, D.; Zaragozí-Alonso, R.; PenarrochaDiago, M.; Penarrocha-Diago, M. The All-on-four treatment concept: Systematic review. J. Clin. Exp. Dent. 2017, 9, e474-e488. [CrossRef] [PubMed]

[10] Maló, P.; de Araújo Nobre, M.; Moura Guedes, C.; Almeida, R.; Silva, A.; Sereno, N.; Legatheaux, J. Shortterm report of an ongoing prospective cohort study evaluating the outcome of full-arch implant-supported fixed hybrid polyetheretherketone-acrylic resin prostheses and the All-on-Four concept. Clin. Implant Dent. Relat. Res. 2018, 20, 692-702. [CrossRef]

[11] Horita S, Sugiura T, Yamamoto K, Murakami K, Imai Y, Kirita T. Biomechanical analysis of immediately loaded implants according to the "All-on-Four" concept. J Prosthodont Res 2017; 61:123-32.

[12] Maló P, de Araújo Nobre M, Lopes A, Ferro A, Gravito I. All-on-4® treatment concept for the rehabilitation of the completely edentulous mandible: A 7-year clinical and 5-year radiographic retrospective case series with risk assessment for implant failure and marginal bone level. Clin Implant Dent Relat Res 2015; 17:531-41.

[13] Manor Y, Simon R, Haim D, Garfunkel A, Moses O. Dental implants in medically complex patients-A retrospective study. Clin Oral Investig 2017; 21:701-8.

[14] Ho CK. Implant rehabilitation in the edentulous jaw: The all-on-4 immediate function concept. Aust Dent J 2012; 23:138-48.

[15] Larsson C, von Steyern PV. Implant-supported full arch zirconia-based mandibular fixed dental prostheses. Eight-year results from a clinical pilot study. Acta Odontol Scand 2013; 71:1118-22.

[16] Degidi M, Nardi D, Piattelli A. Prospective study with a 2-year follow-up on immediate implant loading in the edentulous mandible with a definitive restoration using intra-oral welding. Clin Oral Implants Res. 2010 Apr; 21(4):379-85. http://dx.doi.org/10.1111/j.16000501.2009.01865.x. PMid: 20128829.

[17] Khatami AH, Smith CR. "All-on-Four" immediate function concept and clinical report of treatment of an 
edentulous mandible with a fixed complete denture and milled titanium framework. J Prosthodont. 2008 Jan; 17(1):47-51. http: //dx.doi.org/10.1111/j.1532849X.2007.00246.x. PMid: 17931367.

[18] Tallarico M, Canullo L, Pisano M, Peñarrocha-Oltra D, Peñarrocha-Diago M, Meloni SM. An up to 7-Year Retrospective Analysis of Biologic and Technical Complication with the All-on-4 Concept. J Oral Implantol. 2016; 42(3):265-271.

[19] Cope JB, McFadden D. Temporary replacement of missing maxillary lateral incisors with orthodontic miniscrew implants in growing patients: rationale, clinical technique, and long-term results J Orthod. 2014; 41:s62-74. https://doi.org/10.1179/1465313314Y.0000000112.

[20] Attard NJ, Zarb GA. Long-term treatment outcomes in edentulous patients with implant-fixed prostheses: the Toronto study. Int J Prosthodont. 2004; 17:417-24.

[21] Antonio Scarano, Marco Stoppaccioli and Tommaso Casolino. Zirconia crowns cemented on titanium bars using CAD/CAM: a five-year follow-up prospective clinical study of 9 patients. BMC Oral Health (2019) 19:286

[22] Aaron Yu-Jen Wu, Jui-Ting Hsu, Lih-Jyh Fuh, Heng-Li Huang. Biomechanical effect of implant design on four implants supporting mandibular full-arch fixed dentures: In vitro test and finite element analysis. Journal of the Formosan Medical Association (2020) 119, 1514e1523

[23] Vanessa Araujo SILVA, Allyson Henrique de Andrade FONSECA, Dimitri Ribas FONSEC (in memoriam), Paulo Isaías SERAIDARIAN. Biomechanical development and evaluation of a new framework for allon-four rehabilitation. Rev Odontol UNESP. 2019; 48:e20180123. DOI: https://doi.org/10.1590/18072577.12318

[24] Miguel de Araújo Nobre, Carlos Moura Guedes, Ricardo Almeida, António Silva and Nuno Sereno. Hybrid Polyetheretherketone (PEEK)-Acrylic Resin Prostheses and the All-on-4 Concept: A Full-Arch ImplantSupported Fixed Solution with 3 Years of Follow-Up. J. Clin. Med. 2020, 9, 2187; doi: 10.3390/jcm9072187

[25] Rubo JH, Souza EA. Finite element analysis of stress in bone adjacent to dental implants. J Oral Implantol 2008; 34:248-55.

[26] El-Zawahry MM, El-Ragi AF, El-Anwar MI, Ibraheem EM. The biomechanical effect of different denture base materials on the articular disc in complete denture wearers: a finite element analysis. OA Maced J Med Sci. 2015; 3(3):455-461. (doi: 0.3889/oamjms.2015.074).
[27] João Paulo Mendes Tribst, Dayana Campanelli de Morais, Alexandre Abhdala Alonso, Amanda Maria de Oliveira Dal Piva, Alexandre Luis Souto Borges. Comparative three-dimensional finite element analysis of implant-supported fixed complete arch mandibular prostheses in two materials. J Indian Prosthodont Soc 2017; 17:255-60

[28] Horita S, Sugiura T, Yamamoto K, Murakami K, Imai Y, Kirita T. Biomechanical analysis of immediately loaded implants according to the "All-on-Four" concept. J Prosthodont Res 2017; 61:123-32

[29] Anju Kumari, Puja Malhotra, Shefali Phogat, Bhupender Yadav, Jaiveer Yadav, Sumit Singh Phukela. A finite element analysis to study the stress distribution on distal implants in an all-on-four situation in atrophic maxilla as affected by the tilt of the implants and varying cantilever lengths. J Indian Prosthodont Soc 2020; 20:409-16.

[30] El-Anwar MI, Mohammed MS. Comparison between two low profile attachments for implant mandibular overdentures. Journal of Genetic Engineering and Biotechnology. 2014; 12(1): 45-53. (Doi:10.1016/j.jgeb.2014.03.006)

[31] EL-Anwar MI, Aboelfadl AK. Comparing Different Bar Materials for Mandibular Implant Supported Overdenture: Finite Element Analysis. Indian J Dent Res. 2019; 30(5):716-721.

[32] Vafaei F, Khoshhal $M$ et al. Comparative stress distribution of implant-retained mandibular ballsupported and bar -supported overlay dentures: a finite element analysis.J Oral Implantol 2011; 37(4): 421-429.

[33] Ebadian B, Talebi S, et al. Stress analysis of mandibular implant-retained overdenture with independent attachment system: effect of restoration space and attachment height. Gen Dent 2015; 63(1):61-67.

[34] Geng J, Yan W, Xu W, editors. Application of the finite element method in implant dentistry. Springer Science \& Business Media; 2008 Sep 26.

[35] El-Anwar MI, El-Taftazany EA, Hamed HA, Abd ElHay MA. Influence of Number of Implants and Attachment Type on Stress Distribution in Mandibular ImplantRetained Overdentures: Finite Element Analysis. Open Access Maced J Med Sci. 2017; 5(2):244-249.

[36] El-Anwar MI, Yousief SA, Soliman TA, Saleh MM, Omar WS. A Finite element study on stresses distribution of two different attachment designs under implant supported overdenture. The Saudi Dental Journal. 2015; 27(4):201-7. 